\title{
Research On The Problems Of The Application Of Xbrl Financial Statement In Small And Medium Sized Enterprises
}

\author{
Liucheng Zhang ${ }^{1, a}$ \\ ${ }^{1}$ The practice teaching management center,Harbin University of Commerce,Harbin,China \\ azhangliucheng@126.com
}

Keywords: small and medium-sized enterprise financial statements

\begin{abstract}
This XBRL has been vigorously promoted at the present stage, but the research on XBRL is mostly focused on the technical level. In this paper, conduct an in-depth study of the existing problems about the application of the XBRL in small and medium enterprises.And do the basic work of promoting the application of XBRL in small and medium enterprise problem.
\end{abstract}

\section{Introduction}

With the rapid development of economic globaliza-tion and the rapid development of informatization, standard work is becoming more and more im-portant, its role has become increasingly prominent, and it has become an important means of enterprise development and the means of conducting the eco-nomic and trade. All the countries in the world re-gard the standardization and others which closely re-lated with the standardization including product quality certification, quality system certification, product testing and evaluation, calibration and test, as a powerful tool for economic development and technological, promoting, and create a successful experience. In our national strategy of informatiza-tion,we have definitely put forward the target "in-formatization drive the industrialization",and the standards of informatization is an important means to promote the informatization and to confirm the realization of the value of informatization, the Min-istry of science put the technology standard strategy as three strategies in new era, MIIT also put industry standards as an important guarantee to promote the further development of information industry. In June 26, 2009, China's national standardization system construction project officially started.

XBRL at this stage has been vigorously promoted, but research on the XBRL are mostly concentrated at the technical level, for XBRL basic theory research is still in the initial stage, which may lead to information classification standard.Lacking of theoretical support, the internal organization of the XBRL reporting is also lack of the necessary level and the structure, the relationship among information is not reasonably explained. On the current situation of the application of XBRL in China, the basic theory of the XBRL research still has a lot of blank points.

\section{XBRL own defects}

Limited to the traditional financial report.XBRL Internet financial reporting has some ad-vantages including low cost of transmission, transac-tion time is short, cross platform etc., although XBRL farewells to paper report, and has the above advantages,it will still not get rid of traditional fi-nancial report model.The XBRL still has the follow-ing disadvantages:

First, the accounting information is the traditional financial report, after the audit,which is transformed by the software to get generate XBRL financial re-port, the amount of information is limited to the tra-ditional financial reports, thus affecting the suffi-ciency of the information. With the development of the global economy, the innovation of information technology and the increasing competition of enter-prises, the demand for financial information of the users of financial information becomes more and more large. For example: the disclosure of corporate risk information, intangible assets, corporate reputa-tion, product sales, the production capacity of enter-prises and so on will have a great impact on the fi-nancial situation of enterprises. So the traditional financial report can not meet the needs of the indi-vidual financial statement users. 
Second, the majority of enterprise network financial report content update speed lags behind the pace of change in information, which greatly affects the timeliness of financial information, lag of financial information is not only loss of business opportuni-ties, also will make sellers to feel disappointed with financial information quality . For investors, the his-torical information is the basic of information users making analysis, but the fact is that evaluating enter-prise economic activities and analyzing, predicting the future status of enterprises accounting infor-mation will meet the more needs of information us-ers than historical information. Therefore, the XBRL network financial report needs to break through the traditional financial report information, to realize the sufficiency of financial information, and better play its superiority.

Do not change the accounting information re-porting process. Traditional accounting information reporting process is that conduct accounts adjustment, checkout, ac-count checking to ensure the authenticity and accu-racy of the books and data, then draw up a balance sheet, income statement, cash flow statement and statement of changes in equity and note. traditional accounting information disclosure of a series of methods and techniques is based on abacus, pen, ink, and paper manual information processing tech-niques. Although we now have computers and soft-ware as auxiliary tools, we only use a computerized accounting system to imitate the way of manual pro-cessing and reporting. XBRL Internet financial re-porting is also be used in that way,and did not man-age to use a powerful capability of computer information processing traditional accounting in-formation processing and change the reporting pro-cess.

Avoid accounting based data.The paper-based financial report draws up ledger and general ledger by accounting vouchers ,gathers monthly, quarterly and yearly, draws up summary sheet. Finally draws up the financial statements. Through the paper-based financial report, we can base on the need to learn each data source, view the books even view the bottom basic data for analysis and evaluation. Finally make a decision.

But XBRL financial report compared with the paper financial report, can not reach the ability of tracing the basic data. XBRL network financial report is based on XBRL classification standards,marking each data to map, and conduct converting with the traditional financial report content, and then generate XBRL style sheet. What is showed in front of the information users is only a financial statement and the above figures. Each figure is the remainder of the end of the fiscal year. The information users can not see the basic data behind the figures . Therefore, when the decision makers meet hinders in analysis, evaluation and decision-making, they may avoid the accounting basic data, which is also XBRL own defects.

\section{Small and medium enterprises' security risk by using XBRL}

Internal operational risk.Compared with large and medium-sized enterpris-es,the small and medium-sized enterprises have fea-tures includes that they have small scales, various systems are not perfect, the accounting policies and accounting standards implementation is limited. So there is a variety of security risks ,the main of which is the internal human operation risk.

First of all, the enterprise internal personnel may conduct illegal operation of financial information for a variety of purposes, such as tampering original ac-counting data or modify the program system etc., which will make the accounting information distor-tion and will bring enterprise varying degrees of losses. These defects in the implementation of the accounting system for small and medium enterprises have been in existence, when implementing XBRL in small and medium enterprises, the risk of internal personnel operations will be further expanded in the XBRL environment.

Secondly,XBRL network financial report is drew up more conveniently, after the conversion of tradition-al financial reporting, network financial report is not audited again by auditors. At the same time, XBRL can be quickly provided to any person and organiza-tion, which will make XBRL easily be tampered and attacked. And because of the lack of talents, and the incomprehension of XBRL operating, small and me-dium enterprises can not discover and correct the il-legal operation,sufficient time and internal staff op-erate inappropriately, can also lead to a rise of transmission risks. 


\section{Trade secrets disclosure risk}

Disclosure of commercial secrets is that confidenti-ality of the information is infringed .Business secrets is very important for the enterprise, which is the ba-sis of the healthy development and stable prosperity of an enterprise, the traditional financial report is an-nounced after internal personnel carefully check, so commercial secrets of enterprises generally do not leak, and confidential work will do well. When en-terprises use XBRL Internet financial reporting for external reporting,unlimited authority of XBRL will make plenty of accounting information be sent out-side through the network and will be likely to be il-legally intercepted. It is hard to imagine that in win-ning the competition period, the disclosure of commercial secrets will bring how much loss to the enterprise. It will also consider the network hacker intrusion and computer virus damage. At present, most people has mastered the knowledge of comput-er operations, even become hackers and manufac-tured network virus.They have a variety of purposes on the site to attack, damage the information system, then they will put important financial information on the Internet, which will inevitably make managers of small and medium enterprises concerned.

\section{XBRL network reporting process risk}

Network of XBRL reporting process has the fol-lowing steps: (1)a listed company through internal accounting information system generated relevant accounting information, after accounting firms audit-ing, according to the XBRL Taxonomy, generate XBRL instance document, and put XBRL instance document into the Commission's website.(2)through the FTP server and web browser, the user download the XBRL instance document on the site and use rel-evant software to convert it into HTML, Excel, Word or PDF format for decision makers to use. Af-ter the above process, we can not help worrying about two problems: one is the problem of network security, such as network attacks, hardware failures, software failures, illegal operation, computer virus and so on, which will make network system para-lyzed,and make XBRL report abnormally, even seri-ously affect the XBRL instance document and XBRL information quality. Second is the question of the integrity of information, the converted XBRL instance document is not verified by audit personnel and how to ensure the integrity and reliability of the information from the XBRL instance document pro-vided by company has become the financial report users’ most concerned problem.

\section{Application of small and medium enterprises XBRL encounter resistance}

Basic research lags behind.Because the application of XBRL is still relatively late, a lot of basic theory has not fully formed, such as problems of definition and problems of the standard classification and so on. Without a perfect theoretical foundation assurance, XBRL will be struggling to lose the direction. Our country is still in the stage of development.For example, small and medium-sized enterprises, and other enterprises is lack of understanding of XBRL, many colleges and universities don't set XBRL related courses, and the education of XBRL, promotion and publicity are relatively backward. Some small and medium enter-prises' understanding of XBRL mostly stay in that XBRL will bring enterprise information disclosed,so many companies do not want to use XBRL.So the XBRL basic research still lags behind.

Concerns about the external effects. Only in the economies of scale,the advantages of XBRL be played out better. But at present,the appli-cation of the XBRL in small and medium-sized en-terprises has resistances, Theoretical research is lack of implementation guidance,besides that, concerns of real-time external effect from small and medium enterprises is also a key resistance. From the per-spective of the external environment, companies think that some negative effects will be easy to be produced, because enterprise management worried about that after the application of XBRL, timeliness and transparency of financial information of compa-nies will increase, which will exposed shortcomings and deficiencies of the enterprise, and even leak the enterprise's important trade secrets.All above will impact on enterprise development,and will lead to important losses. If the enterprise makes the com-mercial secrets which is unwilling to be disclosed leaked to the competitors, the loss of enterprises will be difficult to measure. Therefore, due to the con-cerns of the external effects, small and medium en-terprises do not want to use XBRL. 
Talent shortage.XBRL need a high-quality and inter-disciplinary talent team to ensure the effective implementation, these people need to master computer knowledge,principle of computer operation , princi-ple of XBRL technology, application standard, ac-counting knowledge, legal knowledge and other re-lated knowledge. And small and medium enterprises often lack such a compound talents.The reasons mainly lie in two aspects: on the one hand, small and medium-sized enterprises in the talent introduction is relatively weak,the training, the space and post training inputs for the talents are limited; on the oth-er hand, most of the compound talents often choose large enterprises. Therefore, the lack of talent leads to that the implementation of XBRL in small and medium enterprises also encountered some re-sistance.

\section{Conclusions}

XBRL is the technology support that needed by the development of network financial report to the ad-vanced stage,which has been recognized by the in-ternational,It is dedicated to compiling enterprise's financial and commercial reports, conduct infor-mation disclosure for the network environment,and improve the revolutionary information using stand-ard language ability, which is built on the basis of XML and with international standards of open data descriptive language.XBRL can help people achieve business report data and financial data accurate, timely and efficient storage, processing and commu-nication and can make a variety of business infor-mation extracted and exchanged in different soft-ware, platform technology. At present, the application field of foreign countries has covered many aspects, such as capital market, financial su-pervision, tax inspection, business administration, insurance and auditing, etc.. Under the proposal and promotion of China's Ministry of finance, with the advance of the construction of information technolo-gy, XBRL has been gradually applied in the data submitted to the listing Corporation. Unlisted small and medium enterprises encounters all kinds of in-ternal and external resistance, especially enterprise cost control, risk control, personnel training and oth-er aspects, which should be improved.

\section{Acknowledgements}

This work was financially supported by the Natural Social Science Foundation (15BJY017).

\section{References}

[1] Accounting department of the Ministry of fi-nance. Accounting information [J]. China Ac-counting news, 2010,6.

[2] Jia Zhili.XBRL introduction and the application of [J]. accounting research in China, 2010 (5). [3] Peng Ming, Zhu Qiguang: "Research on the development of accounting information in Chi-na" [J]. "financial and accounting communica-tions" in 2011 first.

[4] Gao Yuan, College students' innovative entre-preneurial training plan of project process man-agement research and exploration [J], Journal of laboratory science, 2013 (6), pp. 71-74.

[5] Yang Weizhi, Using the simulation system to cultivate students ability of enterprise manage-ment [J], Journal of laboratory research and ex-ploration, 2013, no. 4, pp. 11-13.

[6] Zhang Li,Applied talents cultivation of innova-tive thinking mode exploration [J], China's higher education, 2012, (19) , pp.12-13 